\title{
Short Rotation Coppice in Italy: a model to asses economic, energetic and environmental performances of different crop systems
}

\author{
Bacenetti Jacopo $^{1 *}$, Fiala Marco ${ }^{1}$ \\ ${ }^{1}$ Department of Agricultural Engineering, Milan, Italy \\ *Corresponding author. Tel: +39 0250316869, Fax: +39 0250316845, E-mail: jacopo.bacenett@unimi.it
}

\begin{abstract}
In the near future, the role that renewable energies can play in order to achieve the ambitious objectives fixed by the European Union is decisive. Besides economic aspect also energetic and environmental issues of agro-energy chains must be carefully evaluated. We developed a software tool able to assess economic, energetic and environmental performance of renewable energy from biomass. The aim of this paper is present the software and its application about one of the most promising energy crop in Italy: Short Rotation Coppice (SRC) based on poplar clones.
\end{abstract}

SRC, subdivided into SRF - plantation with a short cutting frequency (1 or 2 yrs) and in MRF - plantation with a medium cutting time ( 5 yrs), takes up about 7,000 hectares in Italy. Twenty years after their introduction, in bibliography the information concerning this crop is not always clear and unanimous. On the basis of the cultivation technique carried out in Northern Italy, an economic, energetic and environmental (EEE) evaluation of the poplar SRC (SRF and MRF) has been carried out. The analysis is focused on field and transport phases of the agro-energy chain.

Keywords: Short Rotation Coppice (SRC), Poplar, Energy Crops, Energy balance, Sustainability, $\mathrm{CO}_{2}$ balance

\section{Introduction}

In Italy, the contribution of agro-energy to national energy demand is still moderate; nevertheless, even if slowly contributing, its relevance has increased in recent years. Agroenergy seems like a possible and, theoretically, interesting alternative to traditional crops, allowing a diversification of income sources. Compared with other energy sources, the dedicated crops offer the advantage of extremely intense field management that ensures the highest yield as well as the shortest wait time. Cultivation of biomass crops on arable lands allows for increased energy production and should be quite profitable for the environment (groundwater protection, ecological planning, phyto-remediation, and Green House Gases absorption, among other options). This is especially true in the case of woody crops, including Short Rotation Coppice (SRC). Over the last 20 years in Italy, supported by favorable public grant programs, SRC has grown to comprise about 6,500 ha, mainly in the Po Valley area. Leaders in the Lombardy and Veneto Regions have been the first to give subsidies for SRC, and the planting areas in these regions now account for almost all the Italian land area dedicated to this energy crop, 4,000 and 1,300 ha, respectively.

In Italy, the woody species suitable for SRC are Populus spp, Salix spp, black locust, and eucalyptus; however, most plantations consist of specific poplar clones. This arboreus species is historically well-known by Italian farmers and has proven the most adaptable for bio-fuel production. Over the years, the development of new specific clones for biomass production (at the moment, the most important are AF2, Monviso, and Pegaso) and improvement in cultivation techniques have made it possible to obtain remarkable yield increases. Regarding the crop management, several systems with different cutting times have been used: first 1year, and later, 2-year and 5- to 6-year. Different cutting times require different plant densities and different lane widths. The SRC thus can be subdivided into Short Rotation Forestry SRF - plantations with short cutting frequency (1 or 2 years) and (Medium Rotation Forestry) MRF - plantations with medium cutting frequency ( $>5$ years). Planting systems are different, too, with highly variable plant density: 10,000 to 14,000 plants/ha (annual plantation with 
twin rows), 5,000 to 6,000 plants/ha (biennial plantation with single rows) and 1,000 - 1,800 plants/ha (in MRF). In plantations with medium cutting times, the distance between stumps in the row is quite similar to the width of lanes.

At present, even if the best quality bio-fuel comes from 5-year plantations, the larger part of Italian SRC is based on 2-years cuts. In the near future, MRF plantations will be more widespread because of the better quality of chips (mainly due to lower ash content).

Wood chips produced from SRC are a raw material with a low market value (sale prices range from $60 \mathrm{to} 110 € / \mathrm{t}_{\mathrm{dm}}$ ); the economic sustainability of this crop is highly dependent on reduction of production costs. This aim can be reached through high yields as well as through the complete mechanization of all field operations. Among the field operations the harvest is the most difficult because of new, sophisticated equipment with high operating costs. The need for high yield requires high input during the crop cycle that can lessen both energetic and environmental sustainability.

In addition to economic sustainability, energetic and environmental aspects must be considered. Taking into account the considerable public grants given to the main agro-energy chains, researchers should evaluate not only economic sustainability (often achieved by means of public subsidies) but also energetic and environmental sustainability. In this way, a Comprehensive Sustainability could be estimated. Nevertheless, though experts in provide information about this wood-crop, the information is not always clear and unanimous. Regarding SRC energy performances, several values of woody biomass production have been reported $[3,6,8,12,14]$. Discrepancies in results can be attributed mainly to differences in the following factors: species cultivated, calculation methodology, cultivation techniques (i.e., field operations, type, and rate of fertilizers/herbicides), biomass yield, selection of agroenergy chain phases/operations (i.e., storage, transport, drying, conversion process).

Few studies have been conducted to investigate the environmental aspects of energy-crop cultivations, but a number of software tools to assess economic and energy performance of bio-energy production recently have been developed. Nevertheless, most of these tools lack flexibility; their analysis often is restricted to a single type of bio-energy chain or only the main operations of a chain. This makes application of them difficult for the several agroenergy chains actually in use.

Moreover in the future, evaluating the energy-environmental sustainability of each bio-energy chain will become more and more important. Already, before allowing public subsidies, leaders in several Italian regions are calling for energy and environmental evaluations of some bio-energy chains.

In order to overcome the above-mentioned limitations, we have developed a specific tool to assess the comprehensive sustainability of renewable energy produced by farms and easily are able to compare different agro-technical solutions. The software is capable of providing unbiased information on these three aspects (economic, energetic and environmental) of "Comprehensive Sustainability" of this bio-energy chain.

The aim of this work is to show the software tool and present an application regarding Short Rotation Coppice in Italy in order to clarify, 20 years after their introduction, the economic, energetic, and environmental sustainability of SRF and MRF with poplar in northern Italy. 


\section{Methodology}

The software tool works on a farm scale, and the boundaries of the system analyzed are - at the moment - limited to the farm and transport phase of the chain and does not take into account the conversion process. The functional unit is $1 \mathrm{t}_{\mathrm{dm}}$ of biomass. Input required by the software are details of: (a) farm (area, agricultural machinery fleet, crop system); (b) cultivation technique (mechanization operations and sequence; input rate and market prices, energetic and carbon equivalent); and (c) the characteristics of products and byproducts (yields, market prices, lower heating value, and moisture content).

For the economic evaluation, the method of fixed and variable costs [11] is used, while for energy balance computation, the software uses the Gross Energy Requirement (GER) methodology [13]. The environmental analysis takes into account the same input considered in the energy evaluation and assesses the amount of GHG emitted according to guidelines of IPCC [9]. The mass and energy flow between the different operations of the supply chain are converted in economic, energetic, and environmental values, respectively, by using, for each used production factor, the price $\left(\mathrm{P}, € / \mathrm{kg}\right.$ or $\left.€ / \mathrm{m}^{3}\right)$, the energy equivalent $(\mathrm{EE}, \mathrm{MJ} / \mathrm{kg}$ or $\mathrm{MJ} / \mathrm{m}^{3}$ ), and the emission factor (FE, $\mathrm{kg} \mathrm{CO}{ }_{2}$ equivalent $/ \mathrm{kg}$ or $\mathrm{kgCO}_{2} \mathrm{eq} / \mathrm{m}^{3}$ ) [10].

For direct input, the economic, energetic, and environmental load of the production factors is accomplished easily by multiplying the quantity used $\left(\mathrm{Q} ; \mathrm{kg}\right.$ or $\left.\mathrm{m}^{3}\right)$ during the chain as showed in the following equations:

$$
\begin{array}{cc}
\mathrm{C}_{\mathrm{ECO}}=\mathrm{Q} \cdot \mathrm{P} & {[€]} \\
\mathrm{C}_{\mathrm{ENE}}=\mathrm{Q} \cdot \mathrm{EE} & {[\mathrm{MJ}]} \\
\mathrm{C}_{\mathrm{ENV}}=\mathrm{Q} \cdot \mathrm{EF} & {\left[\mathrm{kgCO}_{2} \mathrm{eq}\right]}
\end{array}
$$

where $\mathrm{C}_{\mathrm{ECO}}, \mathrm{C}_{\mathrm{ENE}}, \mathrm{C}_{\mathrm{ENV}}$ are, respectively, the economic, energetic, and environmental costs linked to the different production factors.

In addition to direct input during the cycles of production, others goods are required in order to allow the production of the biomass. These goods are not consumed completely when employed and can be used for several cycles of production. For these production factors, called indirect input, the economic, energetic and environmental cost (EEE cost) $\left(\mathrm{C}_{\mathrm{ECO}}, \mathrm{C}_{\mathrm{ENE}}\right.$, $\mathrm{C}_{\mathrm{ENV}}$ ) is assessed using the same equations adopted for direct input but subdividing their value, the energy, and the greenhouse gases embedded for the overall hours of use and taking into account their economic life (years) and the annual employment (hours).

Therefore, for each production factor, the software computes an EEE cost that summarizes the "load" on the three levels of the analysis. The sum of all the EEE costs allows us to calculate the overall EEE cost for the produced biomass.

To calculate economic net income, the software considers chip-wood selling as well as public subsidies coming from the Rural Development Program (RDP) and Common Agricultural Policy (CAP). Regarding energy aspects, the Lower Heating Value (LHV) of biomass harvested is taken into account to assess the output of these phases of the agro-energy chain. Because the carbon absorbed and stored in the biomass will be oxidized when it will be utilized for energy purposes, this amount cannot be counted as one environmental output. Regarding the $\mathrm{C}$ cycle, the agro-energy chain is supposed to be neutral. The environmental output for the GHG issue must be assessed by comparing the emissions for the energy produced with the agro-energy chain with the emissions of a proper reference system (for 
example, energy produced by a fossil fuel chain). Since at the moment, the software has not yet been implemented with the last phase of the chains, the environmental output cannot be calculated, and the analysis shows just the environmental production cost of the biomass $\left(\mathrm{kgCO}_{2} \mathrm{eq} / \mathrm{t}_{\mathrm{dm}}\right)$. For the functional unit, the software assesses economic, energetic, and environmental cost (EEE Cost), economic and energetic revenues and gains, and the economic and energy ratios (between revenue and cost economic and between output and input energetic, respectively).

By means of the integration of the three EEE costs, the software computes a synthetic index, the Global Sustainability Index (GSI), which summarizes the results achieved on the three levels of the analysis.

\section{Case Studies}

In order to show its applicability, the software was used to evaluate the economic, energetic, and environmental performances of Short Rotation Coppice with poplar in Northern Italy. Two case studies are reported and compared: Short Rotation Forestry (SRF) with 2 years' cutting time and Medium Rotation Forestry (MRF) with 5 years' cutting time.

In both the cases, the crop duration is 10 years, with 2- and 5-year harvests for SRF and MRF, respectively. With respect to the operating conditions of the Po Valley area, the results concerning the conversion from cereals (maize) to poplar for biomass of 40 ha $(50 \%$ of total farm AUA - Agricultural Used Area) are reported.

Table 1 shows the operations required during the entire SRF and MRF poplar cultivationcycle. Table 2 shows the rates for the various production factors. Market prices and energy and environmental equivalents are deduced by bibliography $[1,2,4,5,6,7,10]$.

In the study case, the software tool considers the following: (a) a biomass yield of $40 \mathrm{t}_{\mathrm{wb}} / \mathrm{ha} \cdot \mathrm{yr}$ for SRF and equal to $40 \mathrm{t}_{\mathrm{wb}} / \mathrm{ha} \cdot \mathrm{yr}$ for MRF (moisture content $=55 \%, \mathrm{LHV}=18.5 \mathrm{GJ} / \mathrm{t}_{\mathrm{dm}}$ or $6.9 \mathrm{GJ} / \mathrm{t}_{\mathrm{wb}}$ ); (b) a chip-wood sale price of $35 € / \mathrm{t}_{\mathrm{wb}}$; and for public grants: the decoupling cap (400€/ha·yr) and the planting subsidy provided by leaders in the Lombardy Region (1000 $€ /$ ha).

The transport of the chip wood is carried out by a lorry (load volume: $96 \mathrm{~m}^{3}, 54000 \mathrm{~km} / \mathrm{year}$, $3 \mathrm{~km} / \mathrm{kg}$ of gasoline, bulk density of the chips $=0,3 \mathrm{t} / \mathrm{m}^{3}$, carriage price $=1,7 € / \mathrm{km}$ ). The lorry never travels empty, so the global coefficient of load for a round trip is equal to $100 \%$. We considered two different transport distances of 70 and $450 \mathrm{~km}$ in order to take into account both small- to medium-sized plants in which the biomass supply is prevalently local and large-sized plants in which biomass is collected in a larger area.

\section{Results}

Table 3 shows the EEE Cost for the field phase of the agro-energy chain, with an overall price (selling price is more than public grants) equal to 109.5 and $105.6 € / t_{\mathrm{dm}}$, respectively, for SRF and MRF, and the energy crop allows the farmer a gain of $18,84 € / \mathrm{t}_{\mathrm{dm}}(265 € /$ ha year $)$ for poplar plantations with 2 -year cutting times and of $46.1 € / t_{\mathrm{dm}}(829 € /$ ha $\cdot$ year $)$ for those with 5year cutting time. Consequently, the ratio between economic cost and revenue is equal to 1,18 for SRF and 1,77 for MRF. The energetic aspect of the production cost represents approximately the $6.6 \%$ (for SRF) and the $4.3 \%$ (for MRF) of the $\mathrm{LHV}\left(\mathrm{MJ} / \mathrm{kg}_{\mathrm{wb}}\right.$ ) of the biomass. 
Table 1: Machines and mechanization planning on surface intended for SRC (SRF and MRF) and for traditional crops [4, 5]

\begin{tabular}{|c|c|c|c|c|c|c|}
\hline \multirow{3}{*}{$\begin{array}{l}\text { OPERATION } \\
\text { Pre-planting } \\
\text { Fertilization }\end{array}$} & \multirow{2}{*}{\multicolumn{2}{|c|}{ MACHINE }} & \multirow{3}{*}{$\begin{array}{c}\text { COOPLING } \\
\text { TYPE, } \\
\text { MACHINE } \\
\text { SIZE } \\
\text { TP, } 10 \mathrm{t}, \\
10 \mathrm{~m}^{3}\end{array}$} & \multicolumn{3}{|c|}{$\begin{array}{l}\text { WORKING YEARS } \\
\text { [TIMES PER YEAR] }\end{array}$} \\
\hline & & & & SRF & MRF & MAIZE \\
\hline & $\begin{array}{l}\text { Manure } \\
\text { Spreader }\end{array}$ & $\begin{array}{c}\text { Agricultural } \\
\text { Machinery Fleet }\end{array}$ & & $\begin{array}{c}1 \\
{[\underline{1}]}\end{array}$ & $\begin{array}{c}1 \\
{[\underline{1}]}\end{array}$ & $\begin{array}{c}\text { From } 1 \text { to } \\
10[\underline{1}]\end{array}$ \\
\hline $\begin{array}{l}\text { Primary soil } \\
\text { cultivation }\end{array}$ & Plough & $\begin{array}{c}\text { Agricultural } \\
\text { Machinery Fleet }\end{array}$ & $\begin{array}{c}\mathrm{P}, \\
\text { double- } \\
\text { shovel }\end{array}$ & $\begin{array}{c}1 \\
{[\underline{1}]}\end{array}$ & $\begin{array}{c}1 \\
{[\underline{1}]}\end{array}$ & $\begin{array}{l}\text { From } 1 \text { to } \\
10[1]\end{array}$ \\
\hline $\begin{array}{l}\text { Secondary soil } \\
\text { cultivation }\end{array}$ & $\begin{array}{l}\text { Rotary } \\
\text { harrow }\end{array}$ & $\begin{array}{c}\text { Agricultural } \\
\text { Machinery Fleet }\end{array}$ & $\begin{array}{c}\mathrm{PP} \\
2,40 \mathrm{~m}\end{array}$ & $\left.\begin{array}{c}1 \\
{[\underline{1}]}\end{array}\right]$ & $\left.\begin{array}{c}1 \\
{[\underline{1}]}\end{array}\right]$ & $\begin{array}{c}\text { From } 1 \text { to } \\
10[\underline{1}]\end{array}$ \\
\hline Transplanting & $\begin{array}{l}\text { Planting } \\
\text { Machine }\end{array}$ & Contractor & $\begin{array}{c}\mathrm{T}, \\
\text { bifilar }\end{array}$ & $\begin{array}{c}1 \\
{[\underline{1}]}\end{array}$ & $\left.\begin{array}{c}1 \\
{[\underline{1}]}\end{array}\right]$ & - \\
\hline $\begin{array}{c}\text { Chemical } \\
\text { Weed Control }\end{array}$ & $\begin{array}{l}\text { Spraying } \\
\text { machine }\end{array}$ & $\begin{array}{c}\text { Agricultural } \\
\text { Machinery Fleet }\end{array}$ & $\begin{array}{l}\mathrm{PP}, 15 \mathrm{~m}_{3} \\
1000 \mathrm{dm}^{3}\end{array}$ & $\begin{array}{c}1-3-5- \\
7-9 \\
{[1]}\end{array}$ & $\begin{array}{l}1-6[\underline{2}] \\
2-7[\underline{1}]\end{array}$ & $\begin{array}{l}\text { From } 1 \text { to } \\
10[\underline{1}]\end{array}$ \\
\hline $\begin{array}{c}\text { Pests and } \\
\text { Diseases } \\
\text { Management }\end{array}$ & $\begin{array}{l}\text { Spraying } \\
\text { machine }\end{array}$ & $\begin{array}{c}\text { Agricultural } \\
\text { Machinery Fleet }\end{array}$ & $\begin{array}{l}\mathrm{PP}, 15 \mathrm{~m}_{3} \\
1000 \mathrm{dm}^{3}\end{array}$ & $\begin{array}{c}1-3-5- \\
7-9 \\
{[1]}\end{array}$ & $\begin{array}{c}1-2-6-7 \\
\text { [1] }\end{array}$ & \\
\hline $\begin{array}{c}\text { Cover } \\
\text { Fertilization }\end{array}$ & $\begin{array}{l}\text { Fertilizer } \\
\text { Spreader }\end{array}$ & $\begin{array}{c}\text { Agricultural } \\
\text { Machinery Fleet }\end{array}$ & $\begin{array}{c}\text { PP, } \\
1500 \mathrm{dm}^{3}\end{array}$ & $\begin{array}{c}3-5-7- \\
9 \\
{[1]}\end{array}$ & $6[\underline{1}]$ & $\begin{array}{l}\text { From } 1 \text { to } \\
10[\underline{1}]\end{array}$ \\
\hline $\begin{array}{l}\text { Mechanical } \\
\text { Weed Control }\end{array}$ & $\begin{array}{l}\text { Rotary } \\
\text { harrow }\end{array}$ & $\begin{array}{c}\text { Agricultural } \\
\text { Machinery Fleet }\end{array}$ & $\begin{array}{c}\mathrm{PP} \\
2,40 \mathrm{~m}\end{array}$ & $\begin{array}{c}1-3-5- \\
7-9 \\
{[1]}\end{array}$ & $\begin{array}{c}1-2-6-7 \\
{[2]} \\
3-8[1]\end{array}$ & - \\
\hline $\begin{array}{c}\text { Harvest } \\
\text { Operations }\end{array}$ & $\begin{array}{l}\text { Harvester, } \\
\text { Chipper, } \\
\text { Trailer }\end{array}$ & Contractor & $\begin{array}{l}\text { SPM, } \\
\text { T, PP }\end{array}$ & $\begin{array}{c}2-4-6- \\
8-10 \\
{[1]}\end{array}$ & $\begin{array}{c}5-10 \\
{[1]}\end{array}$ & - \\
\hline $\begin{array}{c}\text { Soil Final } \\
\text { Restoration }\end{array}$ & $\begin{array}{l}\text { Hoeing } \\
\text { Machine }\end{array}$ & Contractor & $\begin{array}{c}\mathrm{P} \\
1,2 \mathrm{~m}\end{array}$ & $\begin{array}{l}10 \\
{[1]}\end{array}$ & $\begin{array}{l}10 \\
{[\underline{1}]}\end{array}$ & - \\
\hline
\end{tabular}

Table 4 shows the EEE cost for transport phase of the chain. Since the characteristics of the biomass are supposed to be unvaried for chips from both SRF and from MRF, the EEE cost for this phase is the same for both types of poplar plantations.

Summing the EEE cost for field and transport phase is possible to calculate the EEE cost for the biomass at the plant mouth of energetic conversion. This cost depends on the cutting time of the plantation as well as on the transport distance between the farm and the conversion plant.

After the field and transport phase, the EEE cost for the SRF plantations is equal to $96.8 € / t_{\mathrm{dm}}$, $499.1 \mathrm{MJ} / \mathrm{t}_{\mathrm{dm}}$, and $65.5 \mathrm{~kg} \mathrm{CO} 2 \mathrm{eq} / \mathrm{t}_{\mathrm{dm}}$ if the distance between the farm and the conversion plant is $70 \mathrm{~km}$, while for longer distances $(450 \mathrm{~km})$, this cost is significantly higher and reaches $151.7 € / \mathrm{t}_{\mathrm{dm}}, 1058.9 \mathrm{MJ} / \mathrm{t}_{\mathrm{dm}}$, and $120.8 \mathrm{kgCO} \mathrm{g}_{2} \mathrm{eq} / \mathrm{t}_{\mathrm{dm}}$. In the case of medium rotation forestry, for the shorter distance, the EEE cost is $63.3 € / t_{\mathrm{dm}}, 343,1 \mathrm{MJ} / \mathrm{t}_{\mathrm{dm}}$, and 44.2 $\mathrm{kgCO} 2 \mathrm{eq} / \mathrm{t}_{\mathrm{dm}}$ and equal to $118.5 € / \mathrm{t}_{\mathrm{dm}}, 902.9 \mathrm{MJ} / \mathrm{t}_{\mathrm{dm}}, 99.4 \mathrm{kgCO}{ }_{2} \mathrm{eq} / \mathrm{t}_{\mathrm{dm}}$ when the distance is $450 \mathrm{~km}$. At the end of the transport operations, the energetic cost represents a variable share of the LHV (MJ $\left./ \mathrm{kg}_{\mathrm{wb}}\right)$ of the biomass: $15,3 \%$ for SRF in which the biomass is transported for a long distance, $7.2 \%$ for SRF when the product is destined to supply small plants, and $13.0 \%$ $(\mathrm{d}=450 \mathrm{~km})$ and $4.9 \%(\mathrm{~d}=70 \mathrm{~km})$ if the wood chips come from MRF. 
Table 2: Production factors utilized within simulation on SRF and MRF [4, 5]

\begin{tabular}{c|c|c|c}
\hline \multirow{2}{*}{$\begin{array}{c}\text { PRODUCTION } \\
\text { FACTORS }\end{array}$} & \multicolumn{3}{|c}{ QUANTITY } \\
\cline { 2 - 4 } & Unit & SRF & MRF \\
\hline Planting material & $\begin{array}{c}\text { cuttings/ha } \\
\text { plant rod/ha }\end{array}$ & 5560 & 1150 \\
\hline $\begin{array}{c}\text { Organic } \\
\text { Manure }\end{array}$ & $\mathrm{t} / \mathrm{ha}$ & 50 & 50 \\
\hline N fertilizer (covering) & $\mathrm{kg} / \mathrm{ha}$ & 320 & 200 \\
\hline Herbicide & $\mathrm{kg} / \mathrm{ha}$ & 20 & 12 \\
\hline Pesticide (pyrethroid) & $\mathrm{kg} / \mathrm{ha}$ & 10 & 4 \\
\hline Water & $\mathrm{m}^{3} / \mathrm{ha}$ & 2000 & 1600 \\
\hline
\end{tabular}

Table 3: Field phase; EEE costs for two different cutting time

\begin{tabular}{|c|c|c|c|}
\hline $\begin{array}{c}\text { EEE COSTS } \\
\text { FIELD PHASE }\end{array}$ & Unit & SRF & MRF \\
\hline Economic & $€ / \mathrm{t}_{\mathrm{dm}}$ & 92,4 & 59,5 \\
\hline Energetic & $\mathrm{MJ} / \mathrm{t}_{\mathrm{dm}}$ & 456 & 301 \\
\hline Environmental & $\mathrm{kg} \mathrm{CO} \mathrm{eq}_{2} / \mathrm{t}_{\mathrm{dm}}$ & 61,5 & 40,1 \\
\hline
\end{tabular}

Table 4: Transport phase; EEE costs for two different distances

\begin{tabular}{|c|c|c|c|}
\hline EEE COSTS & \multirow{2}{*}{ Unit } & \multicolumn{2}{|c|}{ Chip Wood } \\
\cline { 3 - 4 } TRANSPORT PHASE & & $\mathrm{d}=70 \mathrm{~km}$ & $\mathrm{~d}=450 \mathrm{~km}$ \\
\hline Economic & $€ / \mathrm{t}_{\mathrm{dm}}$ & 4,13 & 59,0 \\
\hline Energetic & $\mathrm{MJ} / \mathrm{t}_{\mathrm{dm}}$ & 42,1 & 601,9 \\
\hline Environmental & $\mathrm{kg} \mathrm{CO} 2 \mathrm{eq} / \mathrm{t}_{\mathrm{dm}}$ & 4,15 & 59,1 \\
\hline
\end{tabular}

Comprehensive Sustainability is expressed by all 3 results obtained by the simulation. The smaller the area of the triangle identified by the three costs (economic, energetic, and environmental), the higher the energy-crop sustainability. Figure 1 shows the EEE cost for the different technical solutions studied; in blue are the results for SRF, while MRF results are shown in orange. Regarding the two different transport distances, on the left are shown the results for $\mathrm{d}=70 \mathrm{~km}$, and on the right are shown the results for $\mathrm{d}=450 \mathrm{~km}$.

The Global Sustainability Index, represented by the triangular area, can be calculated by means of Heron's formula. The highest is the GSI, and the lower is the global sustainability of the solution studied. The GSI is 348 and 838 for SRF, while it reaches 617 and 191 for MRF, for short and long transport distances, respectively. 


\section{Discussion and Conclusions}

In the near future, the role that renewable energies can play in order to achieve the ambitious objectives fixed by the European Union is decisive; among the renewable energies, the agroenergy chains appear to be one of the most promising. On the other hand, the development of energy production in agriculture is linked strongly to the possibility that farmers can obtain satisfactory economic results. For this reason, in recent years, several kinds of public grants have been foreseen in order to induce farmers to plant energy crops. In addition to the economic aspects, the energetic and environmental issues also must be taken into account in order to avoid the diffusion of agro-energy chains that are effective from a monetary point of view but not functional regarding the others two topics that determine the Global Sustainability of the chain.

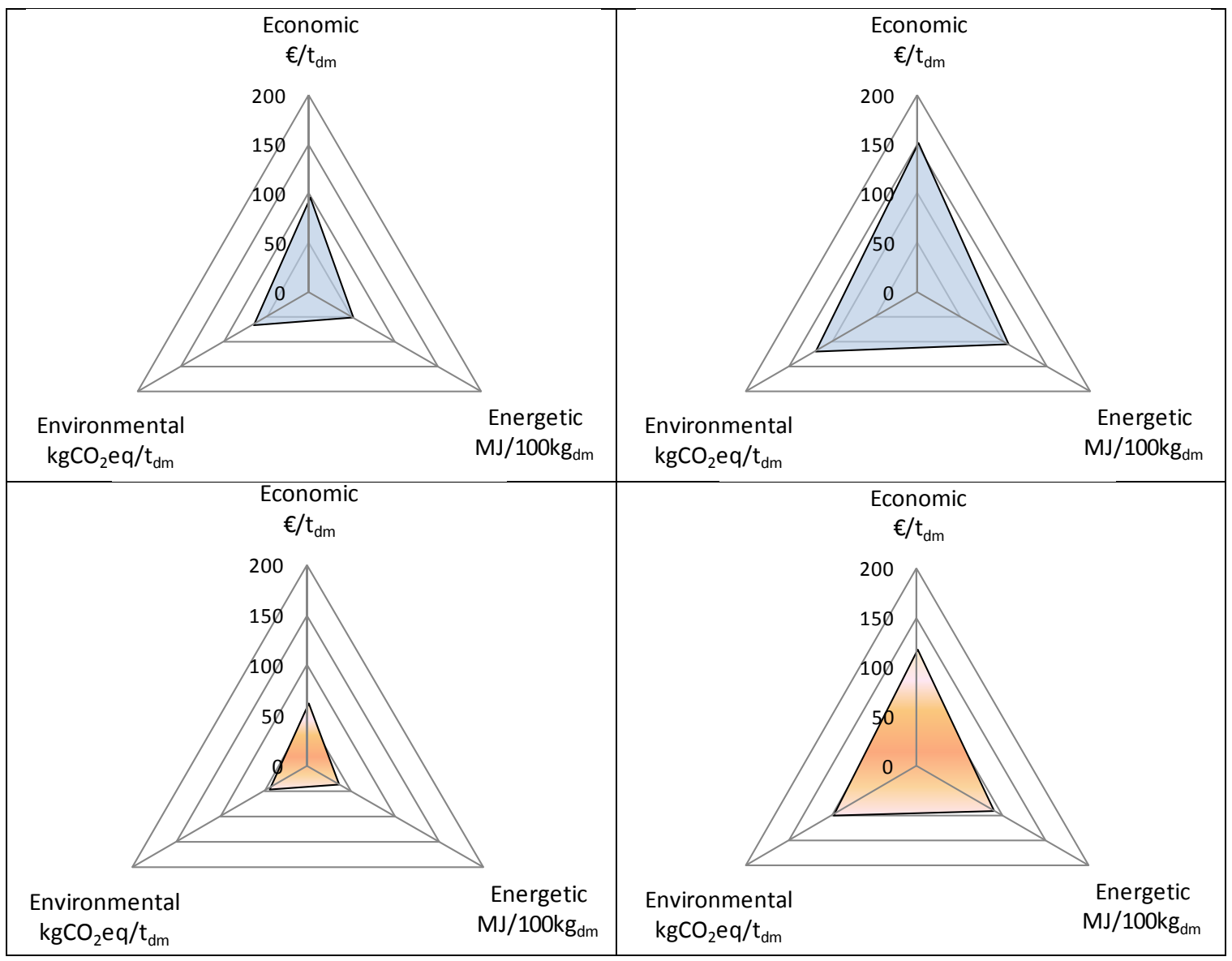

Figure 1 - EEE cost at plant mouth for the different scenarios analyzed

In Italy, good results have been achieved for wood energy crops, and today, a large area of SRC is cultivated. Nevertheless, two different kinds of poplar plantations are still practiced: SRF with short intervals between two harvests and MRF in which the harvests are separated by at least 4 to 5 years. Considering that the production and the transport to the conversion plants are the more energy intensive operations of the agro-energy chains, the present work is focused on the analysis of the economic, energetic, and environmental performances of these phases of the chains, comparing the results between SRF and MRF.

The analysis has been carried out to show that MRF, as compared with SRF, allows farmers to reach better results on all three levels studied. For the MRF, the higher yield and the lower level of input used during the crop cycle (such as nitrogen fertilization) allow the farmer to obtain a better EEE Cost and, consequently, a higher global sustainability. 
Regarding transport, the distance between farm and conversion plant must be evaluated carefully; the EEE cost at plant mouth is significantly higher if the biomass transformation takes place in big plants far from the production area. In this analysis, we supposed that the lorry never travels empty, thus the reduction of the transport cost can be achieved only by the reduction of the distance. Accordingly, the development of several small and medium plants is preferable as opposed to the growth of a few large plants with a very large supply area.

The developed software is a useful tool in order to assess the EEE performances of the different agro-energy chains. Implementation of the last phase of the chains (conversion operations) will allow us to determine not only the agro-energy chain costs but also the output and benefits for the three levels considered.

\section{References}

[1] Bini G., Magistro S., Manuale dei fattori di emissione nazionali, Centro Tematico Nazionale Atmosfera Clima ed Emissioni Aria, Bozza Rapporto n.1, 2002, p. 1-193.

[2] Borjesson P., Energy analysis of biomass production and transportation. Biomass \& Bioenergy, 1996, 11 (4), p. 305-314.

[3] Dubuisson X., Sintzoff I., Energy and $\mathrm{CO}_{2}$ balances in different power generation routes using wood fuel from short rotation coppice. Biomass\&Bioenergy, 1998, 15, p. 79-390

[4] Fiala M. et altri, Short Rotation Coppice in northern Italy: comprehensive sustainability, $18^{\circ}$ European Biomass Conference, Lyon, 3-8 may 2010.

[5] Fiala M., Bacenetti J., Pioppo da biomassa in rotazione biennale,Sherwood, 2010,165.

[6] Heller et al., Life cycle assessment of a willow bioenergy cropping systems. Biomass \& Bioenergy, 2003, 25, p. 147-165.

[7] Jarach M., Sui valori di equivalenza per l'analisi e il bilancio energetici in agricoltura. Rivista di Ingegneria Agraria, 1985, 2, p. 102-114.

[8] Koeleian G., Renewable energy from willow biomass crops: Life cycle energy, environmental and economic performance. Critical Reviews in Plant Sciences, 2005, p. 123

[9] IPCC, Guidelines for National Greenhouse Gas Inventories—Workbook, 1997.

[10] Lai R., Carbon emission from farm operations. Environment International, 2004, 30, p. 981-990.

[11] Lazzari M., Prontuario di Meccanica Agraria e Meccanizzazione, REDA, 2005.

[12] Matthews R., Modelling of energy and carbon budgets of wood fuel coppice systems. Biomass \& Bioenergy, 2001, 21, p. 1-19.

[13] Slesser M., Wallece I., Energy consumption per tonne of competing agricultural products available to the EC (Commission of the European Communities, ed.), Information on Agriculture, 1982, 85, p. 168.

[14] Walle I.V. et al., Short-rotation forestry of birch, maple, poplar and willow in Flanders (Belgium) II. Energy production and $\mathrm{CO} 2$ emission reduction potential. Biomass and Bioenergy, 2007, 31, p. 276-283. 